\title{
Cre-Dependent Optogenetic Transgenic Mice Without Early Age-Related Hearing Loss
}

\author{
Daniel Lyngholm and Shuzo Sakata* \\ Strathclyde Institute of Pharmacy and Biomedical Sciences, University of Strathclyde, Glasgow, United Kingdom
}

With the advent of recent genetic technologies for mice, it is now feasible to investigate the circuit mechanisms of brain functions in an unprecedented manner. Although transgenic mice are commonly used on C57BL/6J (C57) background, hearing research has typically relied on different genetic backgrounds, such as CBA/Ca or CBA due to the genetic defect of C57 mice for early age-related hearing loss. This limits the utilization of available genetic resources for hearing research. Here we report congenic (>F10) Cre-dependent channelrhodopsin2 (ChR2) mice on CBA/Ca background. By crossing this line with Cre-driver mice on C57 background, F1 hybrids restored the hearing deficit of C57 mice. We also found a linear relationship between aging and hearing loss, with progression rates varied depending on genetic backgrounds (3.39 dB/month for C57; $0.82 \mathrm{~dB} /$ month for $\mathrm{F} 1$ hybrid). We further demonstrate that this approach allows to express ChR2 in a specific type of inhibitory neurons in the auditory cortex and that they can be identified within a simultaneously recorded population of neurons in awake mice. Thus, our Cre-dependent optogenetic transgenic mice on CBA/Ca background are a

OPEN ACCESS

Edited by: Christian Gonzalez-Billault, Universidad de Chile, Chile

Reviewed by:

Ting-Ting Huang,

Stanford University, United States

Paul Chadderton,

University of Bristol, United Kingdom

*Correspondence:

Shuzo Sakata

shuzo.sakata@strath.ac.uk

Received: 13 September 2018 Accepted: 01 February 2019

Published: 26 February 2019

Citation:

Lyngholm D and Sakata S (2019) Cre-Dependent Optogenetic Transgenic Mice Without Early Age-Related Hearing Loss.

Front. Aging Neurosci. 11:29. doi: 10.3389/fnagi.2019.00029 valuable tool to investigate the circuit mechanisms of hearing across lifespan.

Keywords: optogenetics, neural circuit, aging, hearing, auditory cortex

\section{INTRODUCTION}

Recent developments in various genetic tools and technologies have revolutionized the investigation of the circuit level mechanisms underlying various behaviors (Yizhar et al., 2011; Deisseroth and Schnitzer, 2013; Wietek et al., 2014; Buzsaki et al., 2015; Rajasethupathy et al., 2016; Roth, 2016; Blackwell and Geffen, 2017; Jun et al., 2017; Gutruf and Rogers, 2018). While mice increasingly play a crucial role in the advancement of neuroscience research, most research is conducted using the C57BL/6J (C57) mouse strain.

A growing number of hearing researchers have also employed advanced optogenetic technologies developed in C57 mice (Seybold et al., 2015; Nelson and Mooney, 2016; Phillips and Hasenstaub, 2016; Sollini and Chadderton, 2016; Blackwell and Geffen, 2017; Guo et al., 2017; Kato et al., 2017). However, because C57 mice are known to develop hearing loss from early age due to a point mutation of $c d h 23$ gene (Willott et al., 1993; Zheng et al., 1999; Noben-Trauth et al., 2003), this poses limitations on hearing research especially when investigating the aging auditory system.

Comparing auditory functions between C57 mice and other genetic backgrounds, such as, CBA or $\mathrm{CBA} / \mathrm{Ca}(\mathrm{CBA})$ mice, has been a popular approach to study the aging auditory system. This approach allows for dissociation of peripheral and central effects of aging on auditory processing (Frisina, 2001; Frisina et al., 2011). However, because of limited availability of transgenic CBA mice, 
transgenic approaches are not straightforward. For example, genetically targeting a specific cell-type in both C57 and CBA backgrounds by utilizing available Cre-driver mice is not currently feasible.

Since C57 × CBA F1 hybrid mice restore the $c d h 23$ mutation (Frisina et al., 2011), generating transgenic mice on a C57 background and then breeding them with CBA wild-type mice can create a valuable transgenic tool for examining the auditory system without early onset hearing loss. However, if the geneof-interest is located on the same chromosome as the cdh 23 gene (i.e., chromosome 10), this approach will require additional considerations (such as genotyping for multiple genes) for an appropriate experimental design.

To address this limitation and to broaden the resource for hearing research, here we present Cre-dependent optogenetic transgenic mice on CBA/Ca background (Ai32 $2^{\mathrm{cba} / \mathrm{ca}}$ ) to express channelrhodopsin2 (ChR2) in a cell-type-specific manner. We developed a congenic ( $>$ F10) line of Ai32 ${ }^{\mathrm{cba} / \mathrm{ca}}$ mice. By crossing a Cre-driver line on C57 background with the Ai32 $2^{\mathrm{cba} / \mathrm{ca}}$ mice (Figure 1A), we confirm that (1) ChR2 can be expressed in the auditory cortex of F1 hybrids in a cell-type-specific manner, (2) the F1 hybrids retain hearing threshold at $>1$ year old compared to transgenic mice on C57 background alone, and (3) ChR2-positive neurons can be identified in vivo. Thus, this Ai32 $2^{\mathrm{cba} / \mathrm{ca}}$ mouse line allows auditory researchers to utilize a variety of Cre-driver mice to express ChR2 in the auditory system and to facilitate studies of the mouse auditory system, in particular in the context of aging.

\section{MATERIALS AND METHODS}

\section{Animals}

All animal experiments were performed in accordance with the United Kingdom Animals (Scientific Procedures) Act of 1986 Home Office regulations and approved by the Home Office (PPL 70/8883). Cre-dependent ChR2-EYFP mice (ChR2 $\left.2^{\mathrm{fl} / \mathrm{fl}}\right), \mathrm{Ai} 32$ mice, (JAX012569) (Madisen et al., 2012) have been backcrossed onto either a CBA/Ca background (Ai32 $2^{\mathrm{cba} / \mathrm{ca}}, \mathrm{F} 18$ to date) or a $\mathrm{C} 57 \mathrm{Bl} / 6 \mathrm{~J}$ background (Ai32 ${ }^{\mathrm{c} 57}, \mathrm{~F} 10$ to date) in house. Mice expressing Cre in either Parvalbumin (PV-Cre) (JAX008069) or Somatostatin (SOM-Cre) (JAX013044) cells were maintained on $\mathrm{C} 57 \mathrm{Bl} / 6 \mathrm{~J}$ background $(\geq \mathrm{F} 6)$ and crossed with either Ai32 $\mathrm{cba} / \mathrm{ca}$ ( $\geq$ F10) or Ai32 ${ }^{c 57}$ ( $\geq$ F6) (Figure 1A). Genotyping for the genetic background of Ai32 mice was designed to determine whether the nucleotide 753 of $c d h 23$ gene is adenine or not. All genotyping was performed by Transnetyx using real-time PCR. $\mathrm{Ai} 32^{\mathrm{cba} / \mathrm{ca}}$ mice tested were all negative whereas Ai32 $2^{\mathrm{c} 57}$ tested were all positive.

Mice were kept for up to 2 years within the local animal facility. To maintain their body weight, low-calorie diet was given from 3 months of age. In the present study, a total of 100 mice (39 PV-Cre ${ }^{\mathrm{c} 57}:: \mathrm{Ai} 32^{\mathrm{c} 57} ; 28$ PV-Cre ${ }^{\mathrm{c} 57}:: \mathrm{Ai} 32^{\mathrm{cba} / \mathrm{ca}}$; 17 SOM-Cre ${ }^{\mathrm{c} 57}:: \mathrm{Ai} 32^{\mathrm{c57}} ; 16$ SOM-Cre $\left.\mathrm{C}^{\mathrm{c57}}: \mathrm{Ai} 32^{\mathrm{cba} / \mathrm{ca}}\right)$ were used. Their age and gender for histological (Figure 1) and electrophysiological studies (Figure 2) are summarized in Tables 1, 2, respectively.

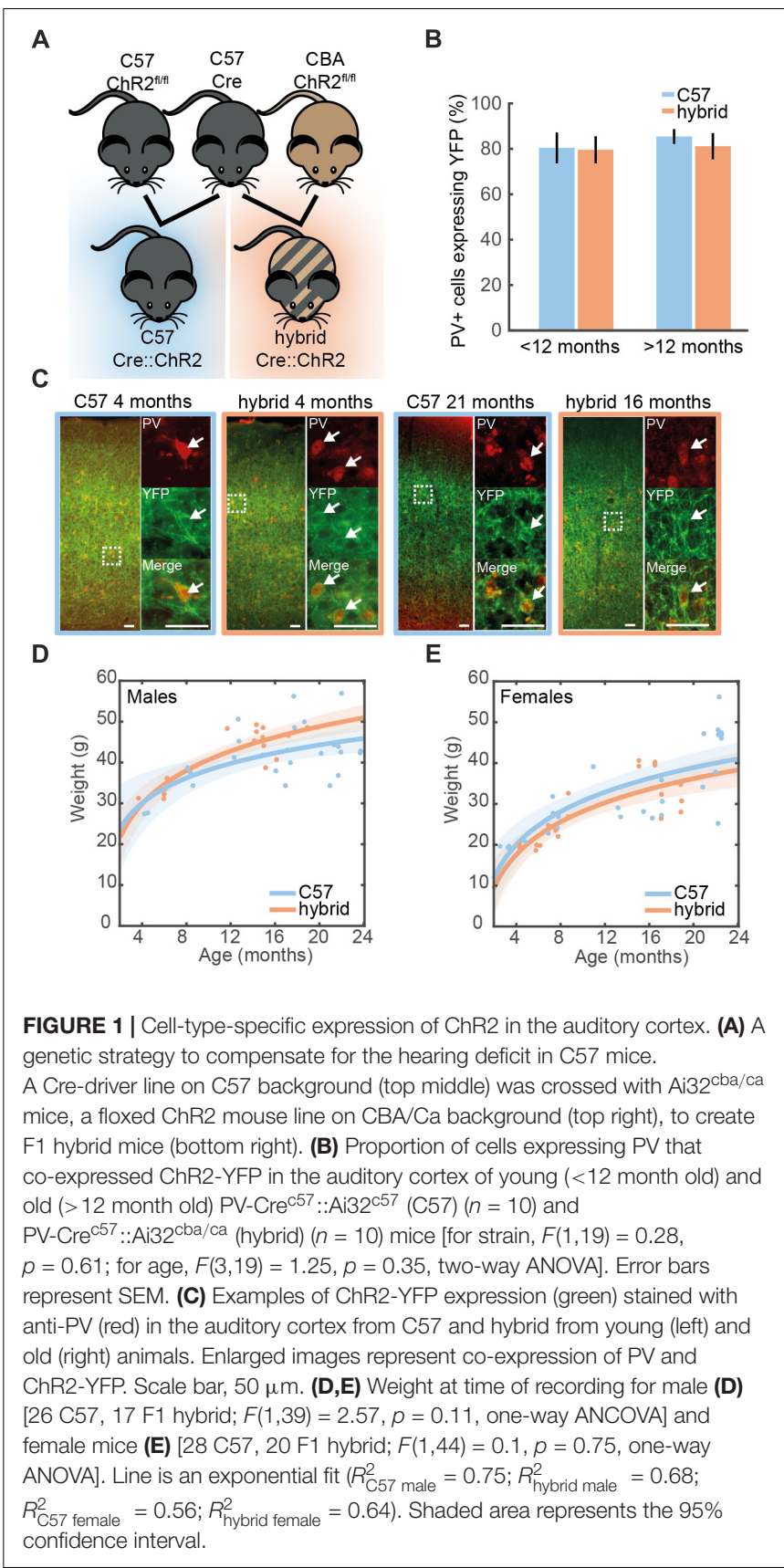

\section{Surgery}

All procedures have been previously described (Yague et al., 2017). Briefly, animals were anesthetized with isoflurane (1-1.5\%). Lidocaine (2\%, $0.1-0.3 \mathrm{mg})$ was administered subcutaneously at the site of incision and Carprofen (Rimadyl, $5 \mathrm{mg} / \mathrm{kg}$ ) was administered intraperitoneally to provide analgesia after the surgery. A head-post was attached on the skull by implanting two frontal bone screws (AP $+3 \mathrm{~mm}$, ML $2 \mathrm{~mm}$ from bregma), one of which was used for cortical electroencephalogram (EEG) recording. Another two screws were implanted over the cerebellum, one of them used as a ground and a reference. A pair of nuts was then attached with 


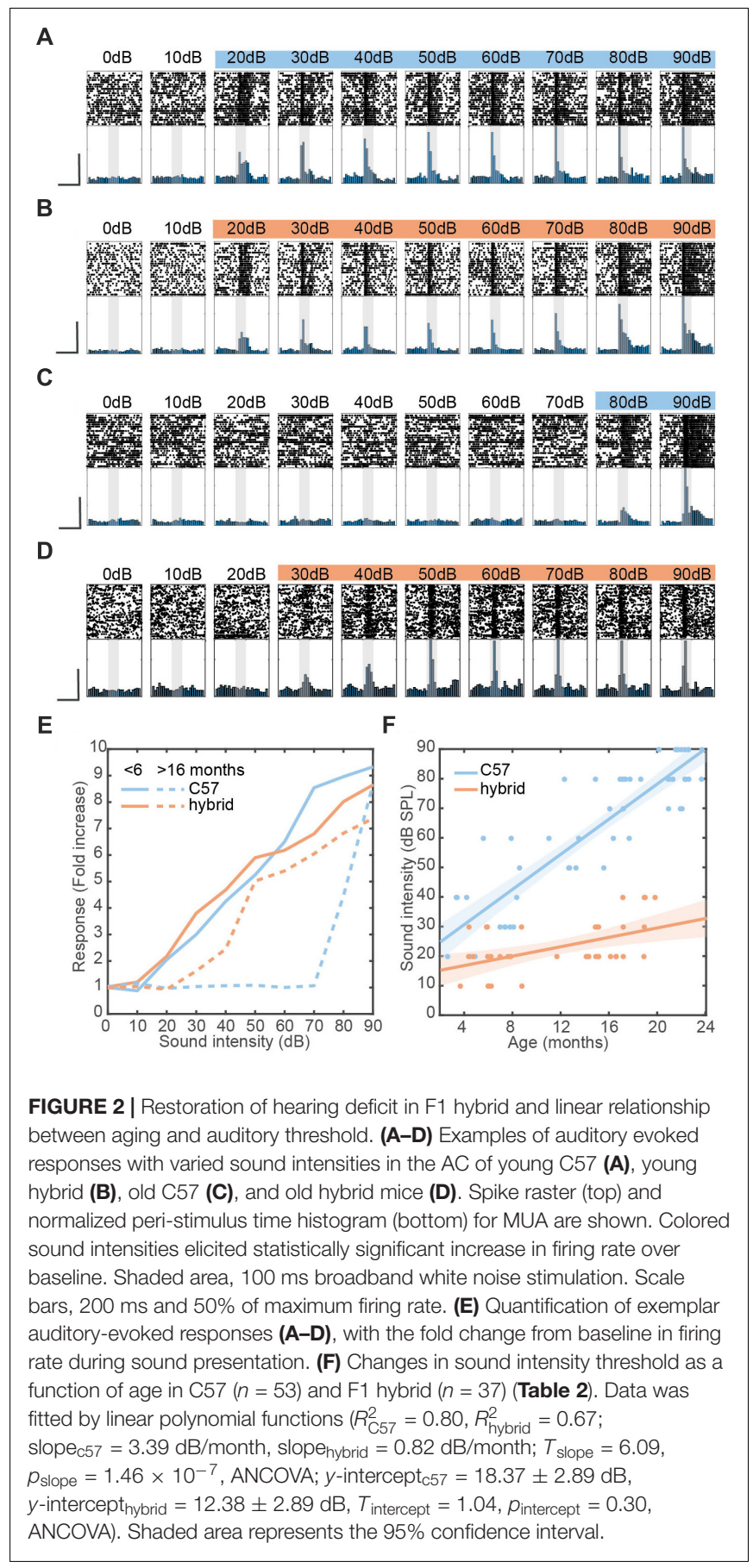

dental cement as a head-post. After the head-post surgery the animals were left to recover for at least 5 days. During an acclimation period of 5 days, the animals were placed in a headfixed apparatus (SR-8N-S, Narishige), by holding them securely by the head-post and placing the animal's body in an acrylic tube. This procedure was continued for at least 5 days, during which the duration of head-fixation was gradually extended from 15 to $60 \mathrm{~min}$. During this period, the animals were also exposed to the sound stimulation in the same manner as the electrophysiological
TABLE 1 | Number of PV animals used for histological analysis.

\begin{tabular}{lccccc}
\hline & \multicolumn{2}{c}{$<$ 12 months } & & \multicolumn{2}{c}{$>12$ months } \\
\cline { 2 - 3 } \cline { 5 - 6 } & C57 & F1 hybrid & & C57 & F1 hybrid \\
Female & 3 & 2 & & 2 & 2 \\
Male & 2 & 3 & & 3 & 3 \\
\hline
\end{tabular}

TABLE 2 | Number of animals used for assessing hearing threshold.

\begin{tabular}{lccccc}
\hline & \multicolumn{2}{c}{$<$ 12 months } & & \multicolumn{2}{c}{$>12$ months } \\
\cline { 2 - 3 } \cline { 5 - 6 } & $\begin{array}{c}\text { C57 } \\
\text { (PV } \mid \text { SOM })\end{array}$ & $\begin{array}{c}\text { F1 hybrid } \\
\text { (PV } \mid \text { SOM) }\end{array}$ & & $\begin{array}{c}\text { C57 } \\
\text { (PV } \mid \text { SOM })\end{array}$ & $\begin{array}{c}\text { F1 hybrid } \\
(\mathbf{P V} \mid \text { SOM })\end{array}$ \\
\hline Female & $11(4 \mid 7)$ & $11(9 \mid 2)$ & & $17(14 \mid 3)$ & $9(4 \mid 5)$ \\
Male & $5(5 \mid 0)$ & $6(3 \mid 3)$ & & $20(13 \mid 7)$ & $11(5 \mid 6)$ \\
\hline
\end{tabular}

recording (see below). A day after this acclimation period, the animals were anesthetized with isoflurane and a craniotomy $(2 \mathrm{~mm} \times 2 \mathrm{~mm}$ at $2.3 \mathrm{~mm}$ posterior and $4.2 \mathrm{~mm}$ lateral to bregma) was performed to expose the primary auditory cortex (AC). The cranial window was protected with a biocompatible sealant (Kwik-Sil, World Precision Instruments). The following day, the animals were placed in the head-fixed condition for electrophysiological recording.

\section{In vivo Electrophysiology}

Detailed recording procedures are the same as those described in previous works (McAlinden et al., 2015; Scharf et al., 2016; Yague et al., 2017). All electrophysiological recordings were performed in a single-walled acoustic chamber lined with three inches of acoustic absorption foam (MAC-3, IAC Acoustics). Mice were head-fixed and either a 32 or 64 channel silicon probe (A1 × 32-10 mm-25 s-177-A32 or A4 × 16-10 mm-50 s-177-A64, respectively, NeuroNexus Technologies) was inserted using a manual micromanipulator (SM-25A, Narishige) for AC recordings. Probes were inserted at a $40-50^{\circ}$ angle to be perpendicular to the cortical surface $(800-1000 \mu \mathrm{m}$ depth from the cortical surface). The location of the electrode in AC was assessed by evaluating the local field potential (LFP) and multiunit activities (MUA) in response to white noise stimulation (see below).

Broadband signals were amplified (RHD2132, Intan Technologies, LLF) relative to the ground and were digitized at $20 \mathrm{kHz}$ (RHD2132 and RHD2000, Intan Technologies, LLC). The recording session was initiated $>30 \mathrm{~min}$ after the probe was inserted to its target depth, to allow for signal stabilization. A typical recording session consisted of $>15$ min baseline recording of spontaneous activity, followed by an optical stimulation protocol, sound presentation, and then another baseline of spontaneous activity.

\section{Optical Stimulation}

Pulses of blue light (450 nm, PlexBright, Plexon) of $100 \mathrm{~ms}$ duration were delivered at $2 \mathrm{~Hz}$ through a $200 \mu \mathrm{m}$ fiber optic (Plexon) attached to the silicon probe and positioned on the 
surface of the brain. The light output at tip of the fiber optic was measured with a constant long ( $>1 \mathrm{~s}$ ) light pulse before probe insertion and was $45 \pm 14 \mathrm{~mW} / \mathrm{mm}^{2}$ (mean $\pm S D$ ).

\section{Sound Presentation}

Sound was generated digitally (sampling rate $97.7 \mathrm{kHz}, \mathrm{RZ6}$, Tucker-Davis Technologies) and delivered in free-field through a calibrated electrostatic loud-speaker (ES1) located $\sim 15 \mathrm{~cm}$ in front of the animal. To estimate the hearing threshold of animals, broadband white noises (100 ms with $5 \mathrm{~ms}$ cosine ramps, $10 \mathrm{~dB}$ steps, 0-90 dB SPL) were pseudo-randomly presented with a minimum of $400 \mathrm{~ms}$ interval for 25 repetitions.

\section{Histology}

For verification of silicon probe tracks, the rear of probes was painted with DiI $(\sim 10 \%$ in ethanol, D282, Life Science Technologies) before probe insertion. After electrophysiological experiments, animals were perfused transcardially with physiological saline followed by $4 \%$ paraformaldehyde $/ 0.1 \mathrm{M}$ phosphate buffer, $\mathrm{pH}$ 7.4. After an overnight post-fixation in the same fixative, brains were stored in 30\% sucrose in phosphate buffered saline (PBS) for cryoprotection. Brains were then cut into $50 \mu \mathrm{m}$ coronal sections with a sliding microtome (SM2010R, Leica) and placed in PBS.

To visualize parvalbumin-positive $(\mathrm{PV}+)$ neurons in PV-Cre ${ }^{\mathrm{c5}}:: \mathrm{Ai} 32^{\mathrm{c57}}$ and PV-Cre ${ }^{\mathrm{c57}}:: \mathrm{Ai} 32^{\mathrm{cba} / \mathrm{ca}}$, immunohistochemistry was also performed. After slicing, a subset of sections were incubated with a blocking solution (10\% normal goat serum, NGS, in $0.5 \%$ Triton $\mathrm{X}$ in PBS, PBST) for $1 \mathrm{~h}$ at room temperature followed by incubating primary antibodies (antiPV 1:4000, P3088, Sigma-Aldrich) in 3\% NGS in PBST at $4^{\circ} \mathrm{C}$ overnight. After washing, sections were incubated with secondary antibodies (Goat anti-mouse Alexa Fluor 568, 1:500, A11007, Life Science Technologies) for $2 \mathrm{~h}$ at room temperature. After washing, sections were mounted on gelatin-coated slides and cover-slipped with antifade solution. Sections were also stained with DAPI (1 $\mu \mathrm{g} / \mathrm{ml}$; Sigma-Aldrich) to determine cortical laminae and structural landmarks used to aid localization of the AC. The sections were mounted on gelatin-coated slides and cover-slipped with antifade solution (Vectashield, Vector Laboratories).

\section{Data Analysis}

Data analysis was performed offline using MATLAB (Mathworks) or freely available software. To extract local field potentials (LFPs), a lowpass filter $(<100 \mathrm{~Hz})$ was applied and signals were downsampled to $1 \mathrm{kHz}$. For spike detection and sorting, the Klusta package (Rossant et al., 2016) or Kilosort (Pachitariu et al., 2016) was used. During visual inspection after this automatic process, events that occurred across all channels were excluded as noise. Other clusters were categorized as either single-unit or multi-unit activity. The quality of clusters was further assessed by measuring isolation distance (SchmitzerTorbert et al., 2005). The inclusion criteria for single units were $\geq 30$ isolation distance and $\geq 0.1 \mathrm{~Hz}$ spontaneous firing. Below, multi-unit activity (MUA) includes both single-unit and multi-unit clusters.
To estimate the hearing threshold of mice, the MUA firing rates during a $50 \mathrm{~ms}$ before and after onset of stimulation were compared. Significance was determined using a Bonferroni corrected Wilcoxon signed-rank test with a 5\% significance level threshold. The hearing threshold was designated as the lowest sound intensity which resulted in a significant increase in the median firing rate. Differences in the hearing threshold between two genetic backgrounds were assessed using twoway analysis of covariance (ANCOVA), with respect to either slope or $y$-intercept.

To determine whether single units were narrow or broad spiking cells, the trough-to-peak duration and width at $20 \%$ of spike amplitude of averaged spike waveforms were computed. Since these measures showed a bimodal distribution, single units were classified into two clusters using spectral $\mathrm{k}$-means clustering implemented using spectral clustering from the Python scikitlearn library (Pedregosa et al., 2011).

To identify single units modulated by optogenetic stimulation in PV-Cre ${ }^{\mathrm{c57}}:: \mathrm{Ai} 32^{\mathrm{c57}}$ and PV-Cre ${ }^{\mathrm{c5}}:: \mathrm{Ai} 32^{\mathrm{cba} / \mathrm{ca}}$ mice (Figure 3), firing rates were compared during a $20 \mathrm{~ms}$ window before and after stimulation using a Bonferroni corrected Wilcoxon signedrank test with a $5 \%$ significance level threshold. Units with a significant increase in the median firing rate during stimulation were classified as positively modulated (presumptive PV+ cells) and units with a significant decrease were classed as negatively modulated cells.

The density functions in Figures $\mathbf{3 G}, \mathbf{H}$ were estimated by fitting a Gaussian kernel to the data as implemented in the Python scikit-learn library (Pedregosa et al., 2011).

\section{Statistical Analysis}

Data was presented as mean \pm SEM unless otherwise stated. Statistical analyses were performed with the Python Statsmodels package. For fitted regression lines, the shaded area around line represents the root mean squared error of the fitted function. In Figure 1B, a two-way ANOVA was performed for age and strain using post hoc Tukey's Honestly Significant Difference (HSD) test. In Figures 1D,E, a logarithmic fit was performed. To test if regression was different between strains, an ANCOVA with post hoc HSD test was performed on log transformed data. In Figure 2F, a linear fit was performed. To compare regression lines, an ANCOVA with post hoc HSD test was performed. Figures 3G,H, a one-way ANOVA was performed and effect size was reported as eta-squared $\left(\eta^{2}\right)$.

\section{Resource Availability}

$\mathrm{Ai} 32^{\mathrm{cba} / \mathrm{ca}}$ mice can be distributed from the corresponding author upon request.

\section{RESULTS}

\section{Database}

A total of 100 mice (39 PV-Cre ${ }^{\mathrm{c57}}:: \mathrm{Ai} 32^{\mathrm{c57}} ; 28 \mathrm{PV}-\mathrm{Cre}^{\mathrm{c} 57}::$ $\mathrm{Ai} 32^{\mathrm{cba} / \mathrm{ca}} ; 17$ SOM-Cre $\left.{ }^{\mathrm{c5}}:: \mathrm{Ai} 32^{\mathrm{c} 57} ; 16 \mathrm{SOM}-\mathrm{Cre}^{\mathrm{c} 57}:: \mathrm{Ai} 32^{\mathrm{cba} / \mathrm{ca}}\right)$ were used. To assess the expression of PV and ChR2 (Figure 1), 10 PV-Cre ${ }^{\mathrm{c57}}:: \mathrm{Ai} 32^{\mathrm{c57}}$ and 10 PV-Cre ${ }^{\mathrm{c57}}:: \mathrm{Ai} 32^{\mathrm{cba} / \mathrm{ca}}$ mice 


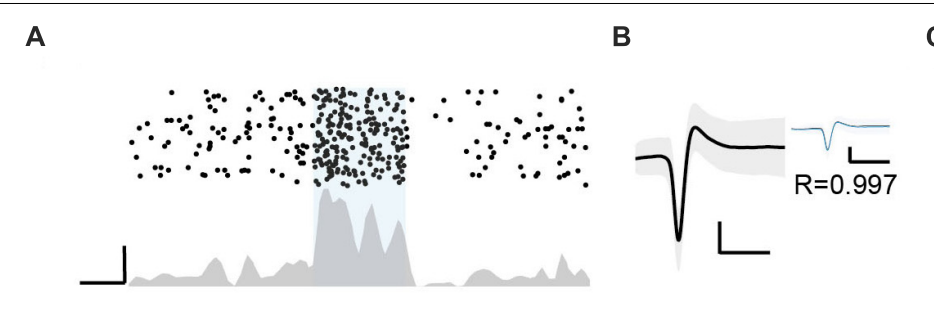

D
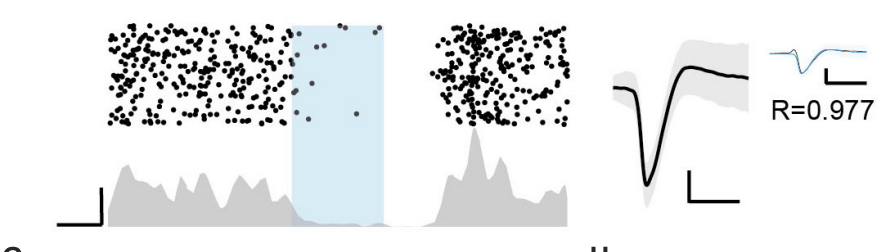

H

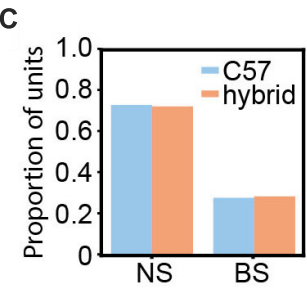

$\mathbf{F}$

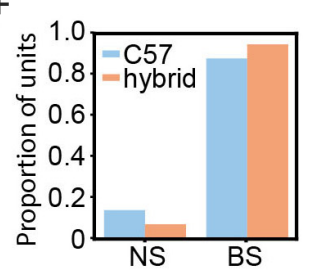

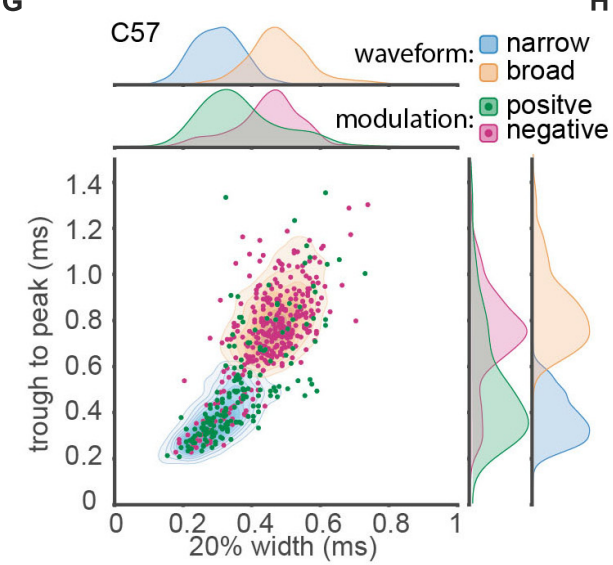

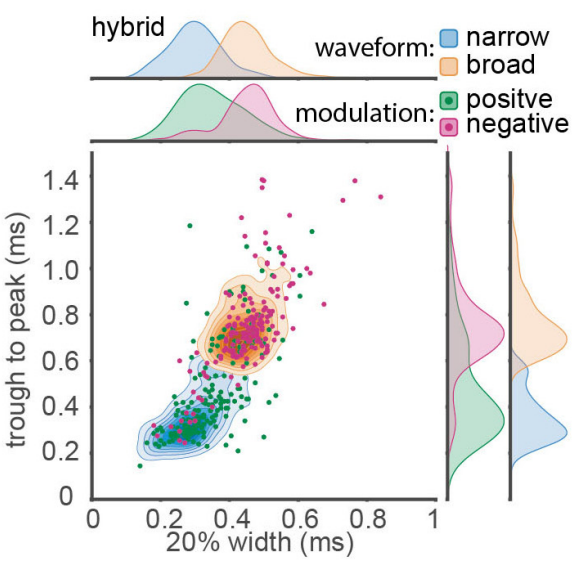

FIGURE 3 | Optogenetic manipulation of auditory cortical PV+ neurons. (A) Raster plot (top) and peri-stimulus time histogram (bottom) for a single unit showing significant positive modulation by optical stimulation in a PV-Cre ${ }^{\mathrm{c} 7}$ ::Ai32 ${ }^{\mathrm{cba} / \mathrm{ca}}$ mouse. Scale bars, $50 \mathrm{~ms}$ and $20 \mathrm{~Hz}$. (B) Average waveform for the same single unit shown in panel (A). Shaded area represents the standard deviation. Inset shows the overlay of average waveform with (blue) and without (black) optical stimulation. $\mathrm{R}$ represents the correlation coefficient between the two average waveforms. Scale bars, $1 \mathrm{~ms}$ and $0.1 \mathrm{mV}$. (C) The proportion of narrow spiking (NS) and broad spiking (BS) cells within optically activated cells in C57 (blue) and hybrid (orange) animals. (D-F) Same as A-C, but for optically suppressed cells. (G,H) Scatter and kernel density plot of trough-to-peak during and $20 \%$ width of spike waveforms across single units in C57 (996 single units from 36 PV-Cre ${ }^{c 57}:$ :Ai32 $2^{\text {c57 }}$ ) (G) and hybrid (759 single units from 21 PV-Cre ${ }^{\mathrm{c} 7}$ ::Ai32 ${ }^{\mathrm{cba} / \mathrm{ca}}$ ) (H). Distributions of NS and BS cells were shown as a density plot (light blue, NS cells; light orange, BS cells), with each density level representing $10 \%$ of the population. Green, optically activated cells. Pink, optically suppressed cells. Distribution of each spike waveform measurement for each cell class was also estimated by using a kernel function analysis.

were used (Table 1). To determine the threshold of neural responses to white noise with varied intensities (Figure 2), we analyzed 111 recordings from 90 animals which included 36 PV-Cre ${ }^{\mathrm{c57}}:: \mathrm{Ai} 32^{\mathrm{c57}}$ and $21 \mathrm{PV}-\mathrm{Cre}^{\mathrm{c57}}:: \mathrm{Ai} 32^{\mathrm{cba} / \mathrm{ca}}$ mice as well as 17 SOM-Cre ${ }^{\mathrm{c} 57}:: \mathrm{Ai} 32^{\mathrm{c57}}$ and 16 SOM-Cre $\mathrm{C}^{\mathrm{c5}}:: \mathrm{Ai} 32^{\mathrm{cba} / \mathrm{ca}}$ mice (Table 2). For in vivo opto-electrophysiological experiments in PV mice (Figure 3), we isolated and analyzed single units from datasets, comprising 53 recordings from $36 \mathrm{PV}-\mathrm{Cre}^{\mathrm{c} 57}:: \mathrm{Ai} 32^{\mathrm{c} 57}$ mice and 24 recordings from 21 PV-Cre ${ }^{\mathrm{c57}}:: \mathrm{Ai} 32^{\mathrm{cba} / \mathrm{ca}}$ mice (Table 3).

\section{Cell-Type-Specific Expression of ChR2 in the Auditory Cortex}

We examined expression of ChR2-EYFP in the auditory cortex (AC) on both genetic backgrounds at different ages (Figure 1C). In young PV-Cre ${ }^{\mathrm{c} 57}:: \mathrm{Ai} 32^{\mathrm{c} 57}$ mice (3-8 month old), we confirmed that $80.4 \pm 6.7 \%$ of $\mathrm{PV}+$ neurons expressed ChR2EYFP in the AC. This trend was held with $85.4 \pm 3.3 \%$ in older animals (16-21 month old) (Figure 1B). Similarly for PV$\mathrm{Cre}^{\mathrm{c57}}:: \mathrm{Ai} 32^{\mathrm{cba} / \mathrm{ca}}$ mice, $79.6 \pm 5.9 \%$ and $81.2 \pm 5.7 \%$ of $\mathrm{PV}+$ neurons expressed ChR2-EYFP in the AC for young (4-12 month old) and old mice (15-21 month old), respectively. We observed no significant differences of expression in either strain $[F(1,19)=0.28, p=0.61$, two-way ANOVA $]$ or age $[F(3,19)=1.25$,

TABLE 3 | Number of single units used for waveform analysis.

\begin{tabular}{ccccccccc}
\hline & \multicolumn{2}{c}{ Positive modulation } & & \multicolumn{2}{c}{ Negative modulation } & & \multicolumn{2}{c}{ No modulation } \\
& C57 & F1 hybrid & & C57 & F1 hybrid & & C57 & F1 hybrid \\
\hline BS & 50 & 51 & & 150 & 79 & & 419 & 335 \\
NS & 133 & 131 & & 24 & 6 & & 220 & 157
\end{tabular}


$p=0.35$, two-way ANOVA] (Figure 1B). We observed no differences in the weight gain between both backgrounds in either female $\left(R_{\text {C57 female }}^{2}=0.56 ; R_{\text {hybrid female }}^{2}=0.64\right)[F(1,44)=0.1$, $p=0.75$, one-way ANCOVA] or male mice $\left(R_{\mathrm{C} 57 \mathrm{male}}^{2}=0.75\right.$; $\left.R_{\text {hybrid male }}^{2}=0.68\right)[F(1,39)=2.57, p=0.11$, one-way ANCOVA $]$ (Figures 1D,E). Thus, both genetic mice are comparable with respect to the weight gain across age and more importantly, $\mathrm{Ai} 32^{\mathrm{cba} / \mathrm{ca}}$ mice allow expression of ChR2 in a Cre-dependent manner in the AC across age.

\section{Linear Relationship Between Aging and Auditory Threshold With Varied Rates}

Early age-related hearing loss in C57 mice is due to a mutation in the $c d h 23$ gene (Noben-Trauth et al., 2003) and a previous report showed crossing $\mathrm{C} 57$ mice with mice on CBA background can restore the hearing loss (Frisina et al., 2011). To confirm whether the F1 hybrid between Cre-driver mice on C57 and $\mathrm{Ai} 32^{\mathrm{cba} / \mathrm{ca}}$ can restore the hearing deficit, we compared auditory cortical evoked responses to broadband white noise with varied sound intensities between both C57 background and the F1 hybrid across age under a head-fixed unanesthetized condition (Figure 2). We took multi-unit activity (MUA) to estimate the sound intensity threshold.

Representative examples of sound-evoked responses are shown in Figures 2A-D. The response profiles across intensities were comparable between the two young mice (3-4 months old) on the two backgrounds (Figures 2A,B). However, a 15 month old C57 mouse showed the detrimental effect of aging on auditory evoked responses (Figure 2C), while a 16 month old F1 hybrid still showed robust evoked responses at lower intensities (Figure 2D). To confirm these trends, we quantified auditory evoked responses across intensities for each animal (Figure 2E).

To further investigate this trend across animals (Table 2), we assessed the sound intensity threshold as a function of age (Figure 2F). Although the initial hearing threshold at 3-4 month old was similar between both strains, threshold progressively increased in C57 mice over 2 years. In contrast, F1 hybrid mice showed smaller changes over the same period (Figure 2F). To quantitatively assess these trends of age-related hearing loss, we fitted data by a simple linear model. While the $y$-intercept for C57 $(18.37 \pm 2.89 \mathrm{~dB})$ and F1 hybrid $(12.38 \pm 2.89 \mathrm{~dB})$ was not significantly different between genetic backgrounds $(T=1.04$, $p=0.30$, ANCOVA), the slope of C57 mice was significantly higher than that of $\mathrm{F} 1$ hybrids (3.39 dB/month for C57 vs. $0.82 \mathrm{~dB} /$ month for F1 hybrids) $\left(T=6.09, p=1.46 \times 10^{-7}\right.$, ANCOVA). Therefore, crossing Cre-driver mice on a C57 background with $\mathrm{Ai} 32^{\mathrm{cba} / \mathrm{ca}}$ can significantly diminish the effect of the genetic defect.

\section{Optogenetic Manipulation of PV+ Neurons in vivo}

To utilize Ai32 $2^{\mathrm{cba} / \mathrm{ca}}$ mice for in vivo optogenetic experiments, we applied optical stimulation to the AC of head-fixed awake PV-Cre ${ }^{\mathrm{c57}}:: \mathrm{Ai} 32^{\mathrm{c57}}(\mathrm{C} 57, n=36)$ and PV-Cre ${ }^{\mathrm{c57}}:: \mathrm{Ai} 32^{\mathrm{cba} / \mathrm{ca}}$ mice (F1 hybrid, $n=21$ ) while auditory cortical ensembles were electrophysiologically monitored by inserting a silicon probe.
Of 1755 single units (996 cells from C57; 759 cells from F1 hybrids), we classified cells based on optical evoked responses (Figures 3A-F) and spike waveforms (Figures 3G,H). Figures 3A,D show two examples of optically activated and suppressed cells, respectively, together with their spike waveforms (Figures 3B,E). In total, we identified 365 (20.8\%) optically activated cells (183 cells from C57; 182 cells from F1 hybrid) and 259 (14.8\%) optically suppressed cells (174 cells from C57; 85 cells from F1 hybrid). The former cells are presumably $\mathrm{PV}+$ neurons.

In parallel, we also classified cells into broad spiking (BS) and narrow spiking (NS) cells based on spike waveforms by measuring trough-to-peak duration (T2P) and the 20\% width of the spike deflection (W20) (Figures 3G,H and Table 3). We obtained 1152 (65.6\%) BS cells (653 cells from C57; 499 cells from F1 hybrid) and 603 (34.4\%) NS cells (343 cells from C57; 260 cells from F1 hybrid).

Based on these two classification approaches, we assessed the proportion of BS and NS cells within optically activated (Figure 3C) and suppressed cells (Figure 3F). In C57 mice, $65.0 \%(119 / 183)$ and $35.0 \%(64 / 183)$ of optically activated cells are NS and BS cells, respectively (Figure 3C). F1 hybrid mice also showed a similar trend (123/182 for NS cells; $59 / 182$ for BS cells). With respect to optically suppressed cells, the majority of them were BS cells (157/174 in C57; $81 / 85$ for F1 hybrid) (Figure $3 F$ ). The mean of spike waveform features was similar in both strains for both T2P $\left[F(1,1751)=0.44, p=0.75, \eta^{2}=0.0002\right.$, one-way ANOVA $]$ and $\mathrm{W} 20\left[F(1,1751)=3.37, p=0.13, \eta^{2}=0.002\right.$, one-way ANOVA $]$, indicating that spike waveform features are comparable between strains. Thus, Ai32 $2^{\mathrm{cba} / \mathrm{ca}}$ mice can be also used for in vivo optogenetic experiments.

\section{DISCUSSION}

To utilize recent genetic technologies in mice for hearing research, we presented Cre-dependent ChR2 mice on CBA/Ca background, Ai32 $2^{\mathrm{cba} / \mathrm{ca}}$ mice. By crossing this line with Cre driver mice on C57 background, we demonstrated (1) cell typespecific expression of ChR2 in the AC, (2) the restoration of early age-related hearing loss in C57 mice, and (3) the capability of optogenetic manipulations in vivo. Thus, this transgenic line offers an opportunity to investigate age-related changes in auditory functions in a cell type-specific manner.

In the present study, we assessed the threshold of auditory evoked responses based on MUAs in the AC. Our results generally agree with the previous report, which examined the same F1 hybrid using auditory brainstem response (ABR) (Frisina et al., 2011) and are broadly in line with previous observations using $\mathrm{ABR}$ in CBA/Ca background (Kane et al., 2012). In addition to replicating the previous finding, we also found a clear linear relationship between age and hearing threshold for the first time (Figure 2E). This linear relationship suggests that age-related hearing loss in C57 mice is an incremental process rather than a sudden change to pathophysiological conditions at a certain time point. Because the effect of the genetic defect seems to be apparent 
even in young ( $<12$ month old) C57 mice, we recommend that studies always report the genetic background. It is important to replicate our results with a larger sample size as well as different assessments including $\mathrm{ABR}$ and tone evoked responses across frequencies in the future.

While we have developed Cre-dependent optogenetic mice on $\mathrm{CBA} / \mathrm{Ca}$ background, there are other approaches to restore the genetic defect of C57 mice. One complementary approach is to generate transgenic mice expressing the gene of interest on the C57 background, and then breed them with mice without the point mutation of $c d h 23$ gene. In addition to wild-type CBA or CBA/Ca mice, B6.CAST-Cdh23 ${ }^{\mathrm{Ahl}+}$ mice can be used because they possess a wild-type $c d h 23$ locus (Keithley et al., 2004). Alternatively, mice created by gene editing technology can be an option. In B6-Cdh23 $3^{\text {c.753G }}$ mice, e.g., the point mutation of $c d h 23$ has been corrected (Johnson et al., 2017).

One caveat for this alternative approach is that if the geneof-interest is located on the same chromosome as the cdh 23 gene (i.e., chromosome 10), this approach will require an extra assessment of their genotype to ensure that both corrected $c d h 23$ and cre are possessed in each animal. An example of this is vasoactive intestinal peptide gene (VIP), which is a maker of a subtype of cortical GABAergic interneurons (Tremblay et al., 2016). To express ChR2 in VIP-positive neurons without early age-related hearing loss, it must be confirmed that ChR2 (i.e., Cre-dependent ChR2 gene) can be expressed in VIP-positive neurons (i.e., Cre+ cells) in animals with the corrected cdh 23 gene, meaning that genotyping for three alleles is required. Therefore, crossing VIP-Cre mice with $\mathrm{Ai} 32^{\mathrm{cba} / \mathrm{ca}}$ will be a more economical option.

\section{REFERENCES}

Blackwell, J. M., and Geffen, M. N. (2017). Progress and challenges for understanding the function of cortical microcircuits in auditory processing. Nat. Commun. 8:2165. doi: 10.1038/s41467-017-01755-2

Buzsaki, G., Stark, E., Berenyi, A., Khodagholy, D., Kipke, D. R., Yoon, E., et al. (2015). Tools for probing local circuits: high-density silicon probes combined with optogenetics. Neuron 86, 92-105. doi: 10.1016/j.neuron.2015.01.028

Deisseroth, K., and Schnitzer, M. J. (2013). Engineering approaches to illuminating brain structure and dynamics. Neuron $80,568-577$. doi: 10.1016/j.neuron.2013. 10.032

Frisina, R. D. (2001). Subcortical neural coding mechanisms for auditory temporal processing. Hear. Res. 158, 1-27. doi: 10.1016/S0378-5955(01)00296-9

Frisina, R. D., Singh, A., Bak, M., Bozorg, S., Seth, R., and Zhu, X. (2011). F1 (CBAxC57) mice show superior hearing in old age relative to their parental strains: hybrid vigor or a new animal model for "golden ears"? Neurobiol. Aging 32, 1716-1724. doi: 10.1016/j.neurobiolaging.2009.09.009

Guo, W., Clause, A. R., Barth-Maron, A., and Polley, D. B. (2017). A corticothalamic circuit for dynamic switching between feature detection and discrimination. Neuron 95, 180.e5-194.e5. doi: 10.1016/j.neuron.2017.05.019

Gutruf, P., and Rogers, J. A. (2018). Implantable, wireless device platforms for neuroscience research. Curr. Opin. Neurobiol. 50, 42-49. doi: 10.1016/j.conb. 2017.12.007

Johnson, K. R., Tian, C., Gagnon, L. H., Jiang, H., Ding, D., and Salvi, R. (2017). Effects of Cdh23 single nucleotide substitutions on age-related hearing loss in C57BL/6 and 129S1/Sv mice and comparisons with congenic strains. Sci. Rep. 7:44450. doi: 10.1038/srep44450

Jun, J. J., Steinmetz, N. A., Siegle, J. H., Denman, D. J., Bauza, M., Barbarits, B., et al. (2017). Fully integrated silicon probes for high-density recording of neural activity. Nature 551, 232-236. doi: 10.1038/nature24636
An obvious application of our Ai32 $2^{\text {cba/ca }}$ mice is for aging research. This genetic line allows to investigate how aging affects the central auditory system at the neural circuit level without early age-related hearing loss. Because C57 and CBA mice have been compared to dissociate between peripheral and central effects of aging processing on the auditory system (Frisina, 2001; Frisina et al., 2011), the same approach can be taken together with optogenetic approaches. Thus, our Ai32 $2^{\mathrm{cba} / \mathrm{ca}}$ mouse line offers an additional toolbox to investigate age-related and cell type-specific changes in aging auditory system.

\section{AUTHOR CONTRIBUTIONS}

DL and SS designed and conceived the experiments and wrote the manuscript. DL performed all the experiments and data analysis.

\section{FUNDING}

This work was supported by BBSRC (BB/M00905X/1), Leverhulme Trust (RPG-2015-377), and Alzheimer's Research UK (ARUK-PPG2017B-005) to SS.

\section{ACKNOWLEDGMENTS}

We thank Amisha Patel and Caroline Wilson for their comments on an early version of the manuscript. We also thank Aimee Bias for her technical assistance.

Kane, K. L., Longo-Guess, C. M., Gagnon, L. H., Ding, D., Salvi, R. J., and Johnson, K. R. (2012). Genetic background effects on age-related hearing loss associated with Cdh23 variants in mice. Hear. Res. 283, 80-88. doi: 10.1016/j.heares.2011. 11.007

Kato, H. K., Asinof, S. K., and Isaacson, J. S. (2017). Network-level control of frequency tuning in auditory cortex. Neuron 95, 412.e4-423.e4. doi: 10.1016/ j.neuron.2017.06.019

Keithley, E. M., Canto, C., Zheng, Q. Y., Fischel-Ghodsian, N., and Johnson, K. R. (2004). Age-related hearing loss and the ahl locus in mice. Hear. Res. 188, 21-28. doi: 10.1016/S0378-5955(03)00365-4

Madisen, L., Mao, T., Koch, H., Zhuo, J. M., Berenyi, A., Fujisawa, S., et al. (2012). A toolbox of Cre-dependent optogenetic transgenic mice for lightinduced activation and silencing. Nat. Neurosci. 15, 793-802. doi: 10.1038/nn. 3078

McAlinden, N., Gu, E., Dawson, M. D., Sakata, S., and Mathieson, K. (2015). Optogenetic activation of neocortical neurons in vivo with a sapphire-based micro-scale LED probe. Front. Neural Circuits 9:25. doi: 10.3389/fncir.2015. 00025

Nelson, A., and Mooney, R. (2016). The basal forebrain and motor cortex provide convergent yet distinct movement-related inputs to the auditory cortex. Neuron 90, 635-648. doi: 10.1016/j.neuron.2016.03.031

Noben-Trauth, K., Zheng, Q. Y., and Johnson, K. R. (2003). Association of cadherin 23 with polygenic inheritance and genetic modification of sensorineural hearing loss. Nat. Genet. 35, 21-23. doi: 10.1038/ng1226

Pachitariu, M., Steinmetz, N. A., Kadir, S. N., Carandini, M., and Harris, K. D. (2016). "Fast and accurate spike sorting of high-channel count probes with Kilosort. Advances in neural information processing systems," in Proceedings of the Advances in Neural Information Processing Systems 29, eds D. D. Lee, M. Sugiyama, U. V. Luxburg, I. Guyon, and R. Garnett (New York, NY: Curran Associates, Inc), 4448-4456. 
Pedregosa, F., Varoquaux, G., Gramfort, A., Michel, V., Thirion, B., Grisel, O., et al. (2011). Scikit-learn: machine learning in python. J. Mach. Learn. Res. 12, 2825-2830.

Phillips, E. A., and Hasenstaub, A. R. (2016). Asymmetric effects of activating and inactivating cortical interneurons. eLife 5:e18383. doi: 10.7554/eLife.18383

Rajasethupathy, P., Ferenczi, E., and Deisseroth, K. (2016). Targeting neural circuits. Cell 165, 524-534. doi: 10.1016/j.cell.2016.03.047

Rossant, C., Kadir, S. N., Goodman, D. F. M., Schulman, J., Hunter, M. L. D., Saleem, A. B., et al. (2016). Spike sorting for large, dense electrode arrays. Nat. Neurosci. 19, 634-641. doi: 10.1038/nn.4268

Roth, B. L. (2016). DREADDs for neuroscientists. Neuron 89, 683-694. doi: 10. 1016/j.neuron.2016.01.040

Scharf, R., Tsunematsu, T., McAlinden, N., Dawson, M. D., Sakata, S., and Mathieson, K. (2016). Depth-specific optogenetic control in vivo with a scalable, high-density muLED neural probe. Sci. Rep. 6:28381. doi: 10.1038/srep28381

Schmitzer-Torbert, N., Jackson, J., Henze, D., Harris, K., and Redish, A. D. (2005). Quantitative measures of cluster quality for use in extracellular recordings. Neuroscience 131, 1-11. doi: 10.1016/j.neuroscience.2004.09.066

Seybold, B. A., Phillips, E. A. K., Schreiner, C. E., and Hasenstaub, A. R. (2015). Inhibitory actions unified by network integration. Neuron $87,1181-1192$. doi: 10.1016/j.neuron.2015.09.013

Sollini, J., and Chadderton, P. (2016). Comodulation enhances signal detection via priming of auditory cortical circuits. J. Neurosci. 36, 12299-12311. doi: 10.1523/JNEUROSCI.0656-16.2016

Tremblay, R., Lee, S., and Rudy, B. (2016). GABAergic interneurons in the neocortex: from cellular properties to circuits. Neuron 91, 260-292. doi: 10. 1016/j.neuron.2016.06.033
Wietek, J., Wiegert, J. S., Adeishvili, N., Schneider, F., Watanabe, H., Tsunoda, S. P., et al. (2014). Conversion of channelrhodopsin into a light-gated chloride channel. Science 344, 409-412. doi: 10.1126/science.124 9375

Willott, J. F., Aitkin, L. M., and Mcfadden, S. L. (1993). Plasticity of auditory cortex associated with sensorineural hearing loss in adult C57BL/6J mice. J. Comp. Neurol. 329, 402-411. doi: 10.1002/cne.903290310

Yague, J. G., Tsunematsu, T., and Sakata, S. (2017). Distinct temporal coordination of spontaneous population activity between basal forebrain and auditory cortex. Front. Neural Circuits 11:64. doi: 10.3389/fncir.2017.00064

Yizhar, O., Fenno, L. E., Davidson, T. J., Mogri, M., and Deisseroth, K. (2011). Optogenetics in neural systems. Neuron 71, 9-34. doi: 10.1016/j.neuron.2011. 06.004

Zheng, Q. Y., Johnson, K. R., and Erway, L. C. (1999). Assessment of hearing in 80 inbred strains of mice by ABR threshold analyses. Hear. Res. 130, 94-107. doi: 10.1016/S0378-5955(99)00003-9

Conflict of Interest Statement: The authors declare that the research was conducted in the absence of any commercial or financial relationships that could be construed as a potential conflict of interest.

Copyright (c) 2019 Lyngholm and Sakata. This is an open-access article distributed under the terms of the Creative Commons Attribution License (CC BY). The use, distribution or reproduction in other forums is permitted, provided the original author(s) and the copyright owner(s) are credited and that the original publication in this journal is cited, in accordance with accepted academic practice. No use, distribution or reproduction is permitted which does not comply with these terms. 